\title{
QUESTÕES DE VIAGEM, QUESTÕES DE TRADUÇÃO: MEDIAÇÃO CULTURAL NA OBRA DE ELIZABETH BISHOP
}

Resumo:

Este trabalho estabelece uma aproximação entre a literatura de viagem e a tradução literária e propõe sua complementaridade. Para esse propósito, são confrontadas teorias que lidam com a representação do outro cultural através de disciplinas tais como a Etnografia, os Estudos da Tradução e a Semiótica. A importância das duas atividades para a história brasileira é iluminada no sentido de investigar a mediação cultural realizada pela poeta americana Elizabeth Bishop entre o Brasil e os EUA, através de seu corpus de literatura de viagem e tradução literâria.

PALAVRAS-CHAVE: tradução literâria, literatura de viagem, Elizabeth Bishop, mediação cultural.

Partindo-se do pressuposto de que a literatura de viagem e a tradução literária são dois importantes mecanismos de representação, constituindo-se como poderosos criadores e disseminadores de imagens culturais, sugere-se que as duas atividades, quando exercidas concomitantemente por um mesmo agente, obedecem e são legitimadas por uma mesma ideologia e poética. 0 estudo do caso da poeta norteamericana Elizabeth Bishop, que viveu no Brasil durante cerca de vinte anos, período em que exerceu um importante papel de mediadora cultural entre este e os Estados Unidos, mediação esta exercida principalmente através da literatura de viagem e da tradução literária, ajuda a revelar a atuação decisiva que ambas as atividades vêm desempenhando na história cultural brasileira.

| Mestre em Letras: Estudos Literários (Área de concentração: Literatura Brasileira), 2003. 


\section{EMTESE}

Belo Horizonte, v. 8, p. I-243, dez. 2004

Elizabeth Bishop morou no Brasil entre os anos de 1951 e 1971, periodo em que viveu com a carioca Maria Carlota Costellat Macedo Soares (Lota), sendo por ela apresentada ao meio cultural brasileiro. Esse convívio acabou tornando Bishop uma espécie de embaixadora cultural entre os Estados Unidos e o Brasil, o que inclusive the proporcionou a condecoração com a medalha da Ordem do Rio Branco pelo governo brasileiro, em 1969. Entre diversos trabalhos, Bishop editou uma antologia de poesia brasileira traduzida para o inglês, escreveu artigos para jornais e revistas, foi co-autora de um livro sobre o Brasil publicado pela editora Time-Life, além de ter escrito um extenso volume de cartas, publicadas após sua morte. A própria obra poética de Bishop encontra-se permeada por sua experiência no Brasil, o que pode ser confirmado tanto em seus poemas quanto em seus contos de temática brasileira. Como tradutora Bishop introduziu grandes poetas brasileiros à língua inglesa, como Vinícius de Moraes, Carlos Drummond de Andrade, Manuel Bandeira, Clarice Lispector e João Cabral de Melo Neto. Esse variado corpus pode ser dividido em dois grupos: um composto pelas traduções e outro composto pelos textos que tratam do Brasil e de sua cultura, aqui caracterizados como literatura de viagem. Ao se pretender investigar as relações entre as duas atividades - a literatura de viagem e a tradução literária - realizadas por Bishop, procura-se entender de que forma ambas compõem um mesmo discurso, e como esse discurso é construído.

As relações entre a literatura de viagem e a tradução literária propiciam uma abordagem interdisciplinar, através do confronto de teorias de diversas áreas do conhecimento que investigam a relação com o outro cultural. Esse confronto permite-nos estabelecer uma ponte conceitual entre as duas atividades. A teoria da literatura comparada apresentada por Pageaux e Machado em Da literatura comparada à teoria da literatura (1988), privilegia o estudo imagológico como um dos temas mais antigos e legítimos da literatura comparada. Segundo os autores, a imagologia (o estudo da presença de imagens de uma nação e de uma cultura na literatura) permite situar seu estudo na esfera do cultural, o que a faz dialogar com outras áreas da ciência, como a teoria da tradução, a etnografia e a semiótica.

Para Pageaux e Machado, os viajantes são um dos principais criadores e disseminadores de imagens. Além dos viajantes, Pageaux e Machado destacam o tradutor como importante mediador cultural. 0 estudo da tradução como fenômeno intercultural 
e do tradutor como mediador e criador de imagens é desenvolvido na teoria da reescrita de André Lefevere (1992). Segundo Lefevere, práticas como a antologização, a crítica literária, a historiografia e a tradução possuem um importante papel de representação cultural, ao mediarem, ou mesmo substituírem, a leitura das obras literárias às quais fazem referência, influenciando o leitor e criando imagens de uma obra, autor, literatura ou cultura. A tradução seria, para Lefevere, um dos tipos de reescrita mais poderosos, por projetar a imagem de uma obra/autor/1iteratura em níveis transculturais.

Também a antropologia propicia o estabelecimento de uma ponte teórica entre a literatura de viagem e a tradução literária. A teoria etnográfica pósmoderna representada por nomes como James Clifford, Mary Louise Pratt e Clifford Geertz, evidenciando a textualidade e a subjetividade presentes na construção da etnografia, nos permite estender à literatura de viagem, tradicionalmente definida por essas características, o diálogo teórico que a primeira vem realizando com os estudos de tradução. Esse diálogo parte do ponto de vista de que ambos, o etnógrafo e o tradutor (e acrescentamos, o viajante), transportam conhecimento de uma cultura para outra e, enquanto mediadores culturais, compartilham dilemas e muitas vezes estratégias comuns para enfrentá-1os. 0 transporte de conhecimento entre culturas realizado por ambos pode ser analisado através do conceito de "tradução cultural", que Carbonell define como "um nīvel superior de interação [que] tem lugar sempre que uma experiência estrangeira é internalizada e reescrita na cultura onde a experiência é recebida" (Carbone11,1996:81). O conceito de tradução cultural permite trazer ao contexto mais amplo da cultura (enquanto unidade operacional) as questões levantadas pela teoria da tradução stricto sensu.

Outra possibilidade para o estabelecimento de uma ponte teórica entre a literatura de viagem e a tradução literária é-nos fornecido pela semiótica de Peirce, a partir da abordagem semiótica que Else Vieira (1992) estabelece da tradução literária. Para a autora, a tradução literária pode ser vista como uma representação icônica, cujas características - como a imprecisão, a birreferencialidade e a presença de um intérprete - podem ser encontradas, segundo nossa proposta, também na representação estabelecida pela literatura de viagem.

As ligações estreitas entre a literatura de viagem e a tradução literária podem ser historicamente comprovadas através de sua atuação conjunta em diversos 


\section{EMTESE}

Belo Horizonte, v. 8, p. I-243, dez. 2004

momentos da história cultural brasileira. Essas ligações encontram-se presentes desde o momento fundador de nossa história, o descobrimento, representado pela Carta de Caminha, relato de um viajante que tenta traduzir na linguagem do velho mundo, o novo mundo que vislumbra. A presença de tradutores e viajantes nos primórdios de nossa história pode ser ainda notada no trabalho dos jesuítas, realizado através da tradução das línguas indígenas e da exploração do interior do território. Durante o romantismo a conjunção das duas atividades também teve papel decisivo na criação de nosso romance nacional, como propõe Flora Süssekind (1990). Segundo Süssekind, o romance brasileiro surge no século XIX a partir de um processo antropofágico de tradução e adaptação dos folhetins franceses, aliado à incorporação da figura do narrador presente nos relatos de viagem que abundavam à época. A presença da literatura de viagem e da tradução em nossa formação cultural é tão importante que podemos identificar a primeira como a origem de uma tradição descritiva que prevalece por um longo período em nossa história literária; enquanto a tradução tem sua teoria incorporada ao discurso cultural brasileiro e é tomada como paradigma para discutir certos aspectos de nossa especificidade cultural (Pagano, 1996). A união entre as duas atividades também pode ser notada em nossa história na atuação de grandes tradutores-viajantes estrangeiros, como o inglês Sir Richard Burton (importante viajante e explorador, e responsável pela primeira tradução de uma obra brasileira para a língua inglesa - Iracema, de José de Alencar), o francês Ferdinand Denis (responsável pela primeira tradução da Carta de Caminha para uma língua estrangeira, o francês, e influência decisiva em nosso movimento Romântico), e a própria Elizabeth Bishop, introdutora da poesia moderna brasileira na língua inglesa. Esses viajantes e tradutores ajudaram não só a criar e divulgar imagens de nossa nação e literatura para o estrangeiro, como em alguns momentos influenciaram o modo como nos próprios nos vemos.

As traduções de Elizabeth Bishop são analisadas a partir da teoria da reescrita de André Lefevere. Segundo Lefevere, toda reescrita manipula o original para fazê-1o adequar-se, ou confrontar-se, com a ideologia e a poética vigentes no sistema literário em que a reescrita é produzida. A análise das reescritas envolve, portanto, o levantamento das correntes ideológicas e poetológicas em vigor e do envolvimento do reescritor com ambas. Apesar de cronologicamente pertencer à pós- 
modernidade na literatura americana, Bishop admitia uma ligação consciente à estética do al to modernismo americano, representado por nomes como o de T. S Eliot e Marianne Moore. Também representante do alto modernismo brasileiro é a poesia brasileira traduzida por Bishop, através de nomes como os de Manuel Bandeira, Carlos Drummond e Vinícius de Moraes. Os dois movimentos modernistas, porém, apresentam certas especificidades que se refletem nas reescritas realizadas por Bishop. Adepta da estética imanentista, apolítica, esteticista, anti-lírica e impessoal professada por El iot, Bishop demonstra certa estranheza ao entrar em contato com nosso modernismo e nossa literatura de feição histórico-social, lírica e pessoal, considerando tais características como resquícios do romantismo que ainda não foram apagados. A partir desse ponto de vista, Bishop considera nossa literatura, especialmente nosso modernismo, retrógrado e calcado de valores passadistas. Essa postura se refletirá em suas reescritas, onde afirma o atraso de nossa literatura (ver Introdução à $A n$ anthology of twentieth-century Brazilian poetry (Bishop, 1972)), e no seu método de tradução, de proposta literal e conservadora.

Em concomitância com a sua visão de nossa literatura, os relatos de viagem de Bishop sobre o Brasil apresentam um país primitivo e atrasado. Bishop era adepta de uma visão etnográfica, representada por nomes como Levi-Strauss, que teme pelo desaparecimento das chamadas sociedades primitivas, idealizando-as como entidades puras e originais. Dessa forma, o Brasil que 1he interessava era o Brasil das pessoas simples do interior, da natureza exuberante e dos costumes tradicionais e "primitivos". A alta cultura brasileira era considerada como uma cópia da Européia, não despertando interesse. Seu olhar se voltava apenas para o que considerava pitoresco e original.

Com toda a ambigüidade presente em sua atitude, Bishop definitivamente exerceu um importante papel de mediadora cultural, divulgando nossa literatura moderna nos países em língua inglesa, além de divulgar nossa cultura em geral, seja em seus textos, cartas e demais projetos em que se envolveu. As reticências de Bishop em admitir qualidades, e reconhecer influências de nossa literatura em sua obra, porém, encontram-se alinhadas com sua imagem do país. 0 Brasil que Bishop enxergava funcionaria antes de tudo como um repositório do exótico e do primitivo para a criação literária. Dessa forma, ela só poderia admitir uma influência em relação a 


\section{EMTESE}

Belo Horizonte, v. 8, p. I-243, dez. 2004

imagens, mas não de poética. Mesmo que tenha sofrido influências poéticas, tais influências não poderiam ser reconhecidas e declaradas, mas escamoteadas. Esse posicionamento pode ser visto tanto na caracterização do país presente em sua literatura de viagem (cujo olhar se dirige apenas aos aspectos naturais e pitorescos), como em seu trabalho tradutório (em que aborda nossa literatura como ultrapassada e despida de originalidade), demonstrando um mesmo olhar e uma complementaridade entre as duas práticas. Em uma entrevista de 1978, a repórter pergunta a Bishop: "Você prefere viajar em pessoa ou através da escrita de um poema? [Bishop:] Oh, pessoalmente. É muito mais fácil!! Mas, como poeta, acredito que prefira ambos. Elas são muito diferentes, na verdade" (Bishop, 1996:101). Apesar da afirmativa da última frase, Bishop como ninguém demonstra o quanto viajar e escrever (e traduzir) são, em muitos casos, a mesma coisa.

ABSTRACT :

This work approximates travel literature and literary translation and posits their complementarity. For this purpose, it interconnects theories concerned with the representation of the cultural other across disciplines, such as Comparative Literature, Translation Studies, Ethnography and Semiotics. The importance of the two activities for Brazilian cultural history is highlighted in order to investigate the cultural mediation achieved by the American poet Elizabeth Bishop between the U.S. and Brazil, through her corpus of travel literature and literary translation.

KEY WORDS: 1iterary translation, travel literature, Elizabeth Bishop, cultural representation.

REFERÊNCIAS BIBLIOGRÁFICAS

BISHOP, Elizabeth. Brazil. (with the editors of Life) Life World Library. New York: Time Incorporated, 1962. . "On the railroad named delight". New York Times Magazine, New York, p. 30-31, 84-86, March 7, 1965. - BRASIL, Emanuel (Org.) An anthology of twentiethcentury Brazilian poetry. Middletown: Wesleyan University, 1972. 
BISHOP, Elizabeth. The collected prose. Roberto Giroux (Ed.). New York: Farrar, Straus and Giroux, 1984.

. The complete poems. 1927-1979. New York: Farrar, Straus, and Giroux, 1989.

- Uma arte. As cartas de Elizabeth Bishop. Roberto Giroux (Org.). Trad. Paulo Henriques Brito. São Paulo: Cia. das Letras, 1995.

- Conversations with Elizabeth Bishop. George Monteiro (Ed.). Jackson: University Press of Mississipi, 1996.

CARBONELL, Ovidio. The exotic space of cultural translation. In: ALVAREZ, Roman, VIDAL, M. Carmem-Africa. (Ed.). Translation, power, subversion. Clevedon: Multilingual Matters Ltd., 1996.

CLIFFORD, James. MARCUS, George E. (Ed.) Writing culture. The poetics and politics of etnography. Berkely/Los Angeles: University of California, 1986.

GEERTZ, Clifford. A interpretação das culturas. Rio de Janeiro: Guanabara Koogsn, 1989.

LEFEVERE, André. Translation, rewriting and the manipulation of literary fame. London: Routledge, 1992b.

PAGANo, Adriana. Percursos críticos e tradutórios de uma nação: Argentina e Brasil. 1996. 353 f. Tese (Doutoramento em Literatura Comparada) Faculdade de Letras, Universidade Federal de Minas Gerais, Belo Horizonte.

PAGEAUX, D. H.; MACHADO, A. M. Da literatura comparada à teoria da literatura. Lisboa: Edições 70, 1988.

PRATT, Marie-Louise. Fieldwork in commom places. In: CLIFFORD, James. MARCUS, George E. (Ed.). Writing culture. The poetics and politics of etnography. Berkely/ Los Angeles: University of California, 1986. p. 27-50.

SÜSSEKIND, Flora. O Brasil não é longe daqui. 0 narrador, a viagem. São Paulo: Cia. das Letras, 1990.

VIEIRA, Else Ribeiro. Por uma teoria pós-moderna da tradução. 1992. 265 f. Tese (Doutorado em Literatura Comparada) - Faculdade de Letras, Universidade Federal de Minas Gerais, Belo Horizonte. 